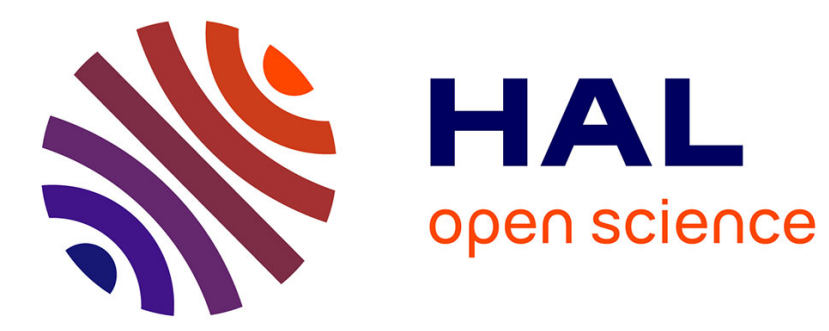

\title{
Somatostatin/somatostatin receptor signalling: Phosphotyrosine phosphatases
}

Tullio Florio

\section{To cite this version:}

Tullio Florio. Somatostatin/somatostatin receptor signalling: Phosphotyrosine phosphatases. Molecular and Cellular Endocrinology, 2008, 286 (1-2), pp.40. 10.1016/j.mce.2007.08.012 . hal-00531947

\section{HAL Id: hal-00531947 \\ https://hal.science/hal-00531947}

Submitted on 4 Nov 2010

HAL is a multi-disciplinary open access archive for the deposit and dissemination of scientific research documents, whether they are published or not. The documents may come from teaching and research institutions in France or abroad, or from public or private research centers.
L'archive ouverte pluridisciplinaire HAL, est destinée au dépôt et à la diffusion de documents scientifiques de niveau recherche, publiés ou non, émanant des établissements d'enseignement et de recherche français ou étrangers, des laboratoires publics ou privés. 


\section{Accepted Manuscript}

Title: Somatostatin/somatostatin receptor signalling:

Phosphotyrosine phosphatases

Author: Tullio Florio

PII: $\quad$ S0303-7207(07)00332-2

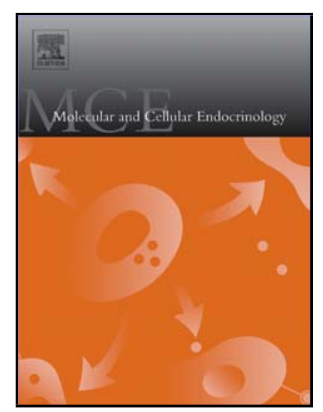

DOI: doi:10.1016/j.mce.2007.08.012

Reference: MCE 6700

To appear in: Molecular and Cellular Endocrinology

Received date: 29-5-2007

Revised date: 27-7-2007

Accepted date:

Please cite this article as: Florio, T., Somatostatin/somatostatin receptor signalling: Phosphotyrosine phosphatases, Molecular and Cellular Endocrinology (2007), doi:10.1016/j.mce.2007.08.012

This is a PDF file of an unedited manuscript that has been accepted for publication. As a service to our customers we are providing this early version of the manuscript. The manuscript will undergo copyediting, typesetting, and review of the resulting proof before it is published in its final form. Please note that during the production process errors may be discovered which could affect the content, and all legal disclaimers that apply to the journal pertain. 


\section{SOMATOSTATIN/SOMATOSTATIN RECEPTOR SIGNALLING: PHOSPHOTYROSINE PHOSPHATASES}

\section{Tullio Florio}

Laboratory of Pharmacology, Department of Oncology, Biology and Genetics, University of Genova, viale Benedetto XV, 2, 16132 Genova, Italy.

Corresponding author:

Tullio Florio, $\mathrm{MD}, \mathrm{PhD}$

Laboratory of Pharmacology, Department of Oncology, Biology and Genetics

University of Genova

Viale Benedetto XV, 2,

16132 Genova, Italy

Tel \& fax: +39-0103538806

E-mail: tullio.florio@unige.it 


\begin{abstract}
Activation of phosphotyrosine phosphatases (PTP) by somatostatin receptor (SSTR) represents one of the main intracellular mechanisms involved in the antiproliferative effect of somatostatin (SST) and analogues. Since their molecular cloning, the role of PTPs is emerging as a major regulator of different cell functions including cell proliferation, differentiation, cell to cell interactions, cell matrix adhesion and cell migration. It was demonstrated that PTPs possess high substrate specificity and their activity is tightly regulated. Importantly, different G protein-coupled receptors transduce their biological activities through PTPs. PTPs were identified as down-stream effectors of SSTRs to transduce antiproliferative signals, and so far, three family members (SHP-1, SHP-2 and DEP-1/PTP $\eta$ ) have been identified as selective SSTR intracellular effectors. Here, the molecular mechanisms leading SSTRs to regulate PTP activity are discussed, focusing on recent data showing a close interplay between PTPs and tyrosine kinases to transduce the tumoral cell growth arrest following SST analogs administration.
\end{abstract}

Key words: somatostatin, somatostatin receptors, phosphotyrosine phosphatase, cell proliferation, apoptosis, MAP kinase, SHP-1, SHP-2, DEP-1/PTP . 


\section{INTRODUCTION}

Somatostatin receptor (SSTR) activation mediates cytostatic effects and cell cycle arrest in G1 or apoptosis, following somatostatin (SST) analogs treatment of tumoral cells in vitro and in vivo (Weckbecker et al., 2003).

Although different intracellular pathways have been recognised to mediate SST inhibition of cell proliferation according to the SSTR subtype studied and to the cell model analyzed, there is now a large consensus about the notion that most of these effects are mediated by the activation of phosphotyrosine phosphatases (PTP) (Weckbecker et al., 2003). In turn, the SST-regulated PTPs control the activity of a number of downstream signalling molecules (in particular the MAP kinase ERK1/2) and, ultimately, induce an up-regulation of cyclin-dependent kinase inhibitors (CDKI), such as $\mathrm{p} 21^{\mathrm{cip} 1 / \mathrm{wafl}}$ and $\mathrm{p} 27^{\mathrm{kip} 1}$. Conversely, the inhibitory effects of SST on cAMP production or $\mathrm{Ca}^{++}$currents are mainly involved in the regulation of hormone secretion in the different target endocrine cells (Weckbecker et al., 2003).

A possible effect of SST on tyrosine phosphorylation signalling was hypothesized on the basis of the observation that SST treatment inhibits the proliferative activity of many tyrosine kinase receptors, in vitro (Bensaid et al., 1992,Cattaneo et al., 1996, Tsuzaki and Moses, 1990,Viguerie et al., 1989). Although early reports showed in gastric cells a phosphatase activity induced after SST treatment (Reyl and Lewin, 1982), the occurrence of a SST-sensitive PTP activity was first described in the MIA-PaCa pancreatic tumor cell line in which the treatment with SST caused an inhibition of EGFR tyrosine phosphorylation (Hierowski et al., 1985). Subsequently, the regulation of PTP activity by SSTRs was directly shown in different tumoral cell types, in which it was demonstrated that this activity was membrane-bound and that G protein activation via SSTRs was required to induce both the PTP activity and the dephosphorylation of tyrosine kinase receptors, such as EGFR (Colas et al., 1992,Pan et al., 1992). An increased PTP activity following treatment with SST or its analogues was then observed in many tumoral cell lines, as well as in primary cell cultures of human tumors, including pituitary adenomas (Ferrante et al., 2006,Florio et al., 1999a,Florio et al., 2003b).

Interestingly, other $\mathrm{G}$ protein coupled receptors, such as the D2 dopamine receptor (Florio et al., 1992), the LHRH receptor (Imai et al., 1996), the angiotensin II receptor (Bedecs et al., 1997) and the adenosine A2a receptor (Murphy et al., 2003) were reported to induce a PTP activity, often (but not always) related to antiproliferative effects. Thus, the regulation of PTP activity is now regarded as a major transducing system for $G$ protein coupled receptors to induce cell growth arrest.

Studies using cells transfected with individual SSTR subtypes have demonstrated that all the 5 members of this receptor subfamily are able to induce PTP activity (Buscail et al., 1994,Florio et al., 
1994,Reardon et al., 1997,Sharma et al., 1996). This activity was identified to be associated with the cell membrane (Colas et al., 1992,Pan et al., 1992) and ascribed to a couple of SH2 domaincontaining PTPs, named SHP-1 and SHP-2 (Bousquet et al., 1998,Florio et al., 2000,Reardon et al., 1997,Srikant and Shen, 1996). Indeed, these cytosolic PTPs were shown to translocate to the cell membrane after their SST-dependent activation (Srikant and Shen, 1996). However, PTP activity was also induced after SST treatment of partially purified membrane preparations in the presence of exogenous GTP (Florio et al., 1996,Pan et al., 1992,Zeggari et al., 1994), suggesting that other members of the PTP superfamily may also be involved in the antiproliferative activity of SST.

Although in many studies the involvement of PTP in the biological effects of SST has been assessed only indirectly through the use of the PTP inhibitor vanadate (Brevini et al., 1993,Ferrante et al., 2006,Sharma and Srikant, 1998), in the past 10 years at least three enzymes of this family (SHP-1, SHP-2 and DEP-1/PTP $\eta$ ) were directly involved in the SST and SST analogues activity and the molecular mechanisms able to transduce the SSTR antiproliferative signals to the cell cycle machinery have been studied in detail.

\section{PHOSPHOTYROSINE PHOSPHATASES}

Ten years after the molecular characterization of the tyrosine kinases, the first PTP, named PTP1B, was purified from human placenta (Tonks et al., 1988), thereby providing "the other side of the coin" regarding how reversible tyrosine phosphorylation is regulated. However, after almost 20 years, the direct modulation of the activity of PTPs is far from to be completely understood. In the human genome about 107 PTPs have been identified, including 38 so-called "classical PTPs" which display an elevated specificity for phospho-tyrosines (Tonks, 2006). The other genes code for a number of dual specificity PTPs (about 65), that dephosphorylate both tyrosines and threonines/serines and other enzymes including myotubularins, low molecular weight PTPs and the lipid phosphatase PTEN (Alonso et al., 2004,Tonks, 2006). Moreover, about 12 pseudogenes for PTPs were identified in the human genome, some of which are transcribed, but their functional significance is still obscure (Andersen et al., 2004). Today, the initial belief that PTPs are mere housekeeping genes with a broad specificity and lack of regulation of activity, has been abandoned and substrate specificity and molecular mechanism of activation were discovered. More importantly, from a functional point of view, it was demonstrated that PTPs have the capacity to regulate the cellular signalling in both a positive and a negative manner (Neel and Tonks, 1997, Tonks, 2006). Classical PTPs are further classified in receptor-like PTPs (RPTPs), characterized by a short transmembrane domain, and cytosolic PTPs (Figure 1) (Tonks, 2006). The phosphatase catalytic domain is about 280 amino acids long and is defined by short sequence motifs including the "phosphatase signature [HCXXGXXR] that functions as a phosphate binding loop at the cysteine 
residue in the active site. The extracellular portion of the RPTPs includes immunoglobulin-like and fibronectin type III domains, features identified in cell-adhesion molecules and possibly implicated in processes that involve cell to cell and cell to matrix contacts. Most RPTP contain, in the intracellular part, two tandem PTP domains (Pan et al., 1993,Tonks and Neel, 2001), although the distal domain (D2), with the exception of the D2 domain of PTP $\alpha$, is catalytically inactive. The significance of this "pseudophosphatase" domain is still not completely understood, although it was proposed to be involved in the structural stability of the whole PTP, and possibly for PTP dimerization. About 9 RPTPs, as well as all the cytosolic PTPs, possess only one PTP domain. Non-transmembrane PTPs contain, flanking the unique catalytic domain, regulatory domains (Figure 1) that control their activity either directly by interaction at the active site (as reported for the SH2 domain of SHP-2) or by regulating the substrate specificity [as reported for PTP-PEST with p130 ${ }^{\text {CAS }}$ (Garton et al., 1996) or STEP and PTP-SL with MAP kinase (Pulido et al., 1998)]. Moreover, these domains control also the subcellular localization, restricting the activity of these PTPs to limited substrates, in specific locations.

To date at least four different mechanisms to modulate the activity of PTPs have been identified. Beside the regulation by $\mathrm{G}$ protein coupled receptors, that is detailed in the following paragraphs and resulting in the activation of the PTPs, PTP activity can be also modulated, mainly in an inhibitory way, by dimerization, ligand binding and reversible oxidation.

The dimerization of RPTPs, in analogy with the activation mechanism of receptor tyrosine kinases, was proposed on the basis of the resolution of the crystal structure of the PTP domains of PTP $\alpha$. These crystals showed the amino-terminus of each monomer inserted like a hairpin in the catalytic site of the other, causing a symmetric occlusion of the active site of the partner molecule (Bilwes et al., 1996). Thus, opposite to tyrosine kinases, dimers of PTP $\alpha$ are catalytically inactive. However, the same interactions were not identified in other PTPs (i.e. LAR and CD45) (Chagnon et al., 2004,Nam et al., 2005), and now the regulation of PTP activity by dimerization is not regarded as a general mechanism of PTP activation.

Due to the receptor-like structure of RPTP for many years the search for extracellular ligands represented a main topic in the biological research, although only recently few potential molecules were identified. The best characterized PTP ligand is the cytokine pleiotrophin that binds to and inhibits the activity of RPTP $\zeta$ (Meng et al., 2000). As a results the phosphorylation of $\beta$-catenin and p190Rho GTPase activating protein (GAP) increases, altering cytoskeleton architecture and cell morphology. Heparan sulphate proteoglycans were shown to bind RPTP $\sigma$, while laminin, is a ligand for LAR and other PTPs that contain in the extracellular portion Ig-like and fibronectin IIIlike domains (Aricescu et al., 2002,Fox and Zinn, 2005) and an agonist for DEP-1 was identified in 
extracellular matrix proteins (Sorby et al., 2001). RPTPs may also act through homophilic interactions (the binding between the extracellular domains of two molecules of the same PTP, in different adjacent cells), as initially demonstrated for PTP $\mu$ (Brady-Kalnay et al., 1993).

More recently, it was shown that reversible oxidation of the catalytically active cysteine may abrogate PTP activity. Oxidation of the PTP domain was identified in many PTPs, including SHP-1 and SHP-2, in response to growth factors, hormones, cytokines and cellular stresses (Tonks, 2005). Although the antagonistic role of PTPs toward tyrosine kinases suggests antioncogenic properties, this assumption is not always true. For example, CD45 activity was recognized to be necessary for cell cycle progression, $\mathrm{PTP} \alpha$ overexpression induces fibroblast transformation via the dephosphorylation of the inhibitory tyrosines of Src or Lck (Zheng et al., 1992) and SHP-2 participate to the intracellular signalling of different growth factor receptors (Ostman et al., 2006). However, both PTP $\alpha$ and SHP-2 may exert positive or negative effects on cell proliferation according to the cell type or the receptor system analyzed, and most PTPs are considered oncosuppressor genes. The antiproliferative potential of PTPs is dependent on their capability to alter growth factor signalling through the selective dephosphorylation and inactivation of their receptors [as reported for DEP-1 with PDGF-R and VEGF-R2 (Kovalenko et al., 2000,Lampugnani et al., 2003), for SHP-1 or SHP-2 with the insulin-R (Bousquet et al., 1998,Florio et al., 2001), PTP1B with the EGFR (Milarski et al., 1993)] or down-stream effectors [ERK1/2 activity is inhibited by PTP-SL, STEP and TC-PTP (Pulido et al., 1998)]. PTPs also interfere with cytoskeleton dynamics. Malignant cells are often characterized by decreased adhesion to substrates that allows a rapid cell proliferation and dissemination. This effect depends on the tyrosine phosphorylation of the cadherin-catenin complex induced by Src, EGFR and HGFR. On the contrary, the activation of PTPs (DEP-1, РTP $\mu$, PTP1B, etc.) causes the dephosphorylation of such proteins and thereby promotes cadherin-mediated cell adhesion (Ostman et al., 2006).

\section{SSTR-DEPENDENT ACTIVATION OF SPECIFIC PTPS}

\subsection{SHP-1}

SHP-1 represents the "classical PTP" more often involved in the antiproliferative activity of SST.

This PTP is a cytosolic enzyme containing a tandem of amino-terminal SH2 domains, a single catalytic domain and two tyrosyl phosphorylation sites at the carboxyl-terminus (Figure 1). The SH2 domains have the double function to recruit the PTP to specific tyrosine phosphorylated proteins (in some cases representing also the catalytic target) and to directly regulate the catalytic activity of the PTP. In the absence of appropriated phosphorylated proteins, the N-terminal SH2 domain binds to and inactivates the PTP domain, a process that can be disrupted by the interaction with phosphotyrosines (Tonks and Neel, 2001). SHP-1 is now considered a tumor suppressor PTP 
since its inactivation, via promoter methylation, was described in many tumor types (Ostman et al., 2006).

SSTR activation of SHP-1 was reported to induce arrest of cell proliferation in different tumor cell lines derived from breast carcinomas (MCF-7), pancreatic cancers (MIA-PaCa, PANC-2, PC-1, PC3), thyroid medullary carcinoma (TT) and pituitary adenomas (GH3), among others (Thangaraju et al., 1999b,Theodoropoulou et al., 2006,Zapata et al., 2002,Zatelli et al., 2005).

Co-immunoprecipitation studies showed that, in CHO cells transfected with SSTR2 and SHP-1, these molecules are assembled in a multiprotein complex regulated by $\mathrm{G}_{\mathrm{i} 3 \alpha}$ (Lopez et al., 1997). In this cell model, the activation of SSTR2 by octreotide promoted the activation of SHP-1 and its dissociation from the receptor. SST-activated SHP-1 rapidly associated to the autophosphorylated insulin receptor, dephosphorylated both the receptor itself and its substrates (i.e. IRS-1, Shc), leading to a negative modulation of insulin mitogenic signals (Bousquet et al., 1998). The antiproliferative activity mediated by SHP-1, following SSTR2 stimulation, was dependent on the inhibition of the entry in the S phase of the cell cycle and accumulation of the cells in G1, through the overexpression of $\mathrm{p} 27^{\mathrm{kip} 1}$ and increase of hypophosphorylated retinoblastoma gene product $(\mathrm{Rb})$ (Pages et al., 1999). It was also shown that the p85 subunit of phosphatidyl inositol 3 kinase (PI3K) is associated to both SHP-1 (Yu et al., 1998) and the first intracellular loop of SSTR2. In pancreatic cancer cells, upon SSTR2 activation, SHP-1 causes p85 dephosphorylation, dissociation from the receptor and inhibition of PI3K activity (Bousquet et al., 2006). Similarly, in pituitary cells SSTR2induced activation of SHP-1 (but not SHP-2) causes the dephosphorylation of p85 and the inhibition of PI3K activity (Theodoropoulou et al., 2006). In this study, the SHP-1 dependent inhibition of PI3K activity was responsible for the inhibition PDK1 and Akt activities that, in turn, resulted in the activation of the glycogen synthase kinase $3 \beta$ (GSK3 $\beta$ ). The enhance of GSK3 $\beta$ activity up-regulated the expression of the onco-suppressor gene Zac1 that ultimately induced growth arrest (Theodoropoulou et al., 2006).

SHP-1 activity was also involved in the SSTR3-dependent apoptosis, in transfected CHO cells (Sharma et al., 1996). In MCF-7 breast carcinoma cells the induction of apoptosis by SST was mediated by an intracellular signalling cascade involving the activation of SHP-1 and caspase 8 and intracellular acidification that caused the activation of the executioner caspases (Liu et al., 2000, Thangaraju et al., 1999a). Interestingly, the induction of apoptosis by SSTR3 was a cell typedependent event, since it was not observed in endothelial cells, when this receptor subtype was activated to block angiogenesis (Florio et al., 2003a), but occurred in human thymocytes (Ferone et al., 2002). 
SHP-1 was also involved in the p53-independent induction of apoptosis, following SSTR2 activation, representing, in pancreatic tumor cells, an absolute requirement for the activation of executioner caspases (Guillermet et al., 2003).

More recently, a completely novel mechanism by which the SSTR2-dependent activation of SHP-1 may cause apoptosis was identified in NIH3T3 cells. It was reported that the activation of SHP-1 by SST analogues activates the transcription factor NFkB causing an inhibition of the anti-apoptotic effects of the MAP kinase JNK and, in turn, hyperactivation caspase 8 and apoptosis (GuillermetGuibert et al., 2007).

\subsection{SHP-2}

SHP-2 was involved in the antiproliferative activity of SST following SSTR1 (Florio et al., 1999b,Florio et al., 2000), SSTR2, SSTR3 and SSTR4 activation (Reardon et al., 1997).

Structurally, SHP-2 is very similar to SHP-1 with the main difference identified in a proline-rich region flanking the tyrosyl phosphorylation sites. However, SHP-1 and SHP-2 display a very different regulation of their activity and biological functions. In fact, SHP-2 was reported to play a positive or negative role in signal transduction according to the cell type and the receptor system analyzed. In particular, SHP-2 is recruited to tyrosine kinase receptors or their scaffold proteins increasing growth factor signalling through the dephosphorylation and activation of ras-GAP or through the removal of the phosphate group from the inhibitory tyrosine in the C-terminus of the kinases of the Src family (Ostman et al., 2006). On the other hand, in response to SSTRs, SHP-2 was involved in the cell growth arrest (Florio et al., 2000). Interestingly, the same molecules involved in the positive effects of SHP-2 on cell growth (JAK2, Src), when activated in a different cell context, were also involved in the antiproliferative effects (see below).

SHP-2 was identified in different tumor cell types responsive to SSTR ligands in vitro, including glioma and thyroid cells. Its activation by SSTRs induce antiproliferative effects via the direct interaction, dephosphorylation and inactivation of the tyrosine kinase receptors for insulin and EGF (Florio et al., 2001,Held-Feindt et al., 2001).

SSTR2, SSTR3 and SSTR4 were also reported to activate SHP-2 (but not PTP1B) in NIH3T3 cells transfected with these receptors (Reardon et al., 1997). Moreover, the PTP activity induced by SSTR2 and SSTR3 activation caused Raf-1 inactivation, blockade of the MAP kinase cascade and cell growth arrest (Dent et al., 1997,Reardon et al., 1996).

Interestingly, in some cell models, the activation of SHP-2 by SST can induce cell cycle arrest also via the activation of MAP kinase. It is known that the effects of ERK1/2 on cell proliferation are related also to the duration and intensity of ERK1/2 activation (Murphy et al., 2002). The activation of both SSTR1 and SSTR2 was reported to induce cell cycle arrest via the hyperactivation of 
ERK1/2 and the up-regulation of $\mathrm{p} 21^{\text {cip1/wafl }}$ and p2 $7^{\text {kip1 }}$, respectively (Florio et al., 1999b,Lahlou et al., 2003). However, the complex intracellular signalling used by the two receptors was only partially overlapping. In particular, the activation of SSTR1 induced ERK1/2 activity regulating, via the beta/gamma subunits of a pertussis toxin-sensitive G protein, Src/SHP-2/PI3K/ras/Raf-1/MEK (Florio et al., 1999b), while the SSTR2-regulated pathway involved SHP-1/SHP-2/PI3K/rap1 and ras/B-Raf/MEK (Lahlou et al., 2003).

\subsection{DEP-1/PTP $\eta$}

Although most studies identified SHP-1 and SHP-2 as effector PTPs after SSTR activation, in some cell types a more complex PTP regulation has been observed. In fact, beside SHP-2 activity, another delayed and long lasting PTP activity was also induced following SST treatment (Florio et al., 2000). Thus, it was proposed that other PTPs could be involved in the SST cytostatic effects. One of these PTPs was identified in a receptor-like PTP named DEP-1 (density enhanced phosphatase-1) in humans (РTP $\eta$ in rats), whose oncosuppressor role was already established (Ostman et al., 2006). This PTP is expressed ubiquitously, showing high levels in the brain, liver and spleen. The predicted protein contains a unique intracellular catalytic domain, a short transmembrane domain and an extracellular region containing eight fibronectin type III-like repeats (Tonks, 2006). Its role as an onco-suppressor gene was proposed after the identification of its gene (Ptprj) in the colon cancer susceptibility locus (Scc1) (Ruivenkamp et al., 2002). Subsequently, many studies suggested that DEP-1/PTP $\eta$ is a negative regulator of cell growth via the inhibition of growth factor receptor activity or increasing the substrate adhesion through Src inhibition (Iuliano et al., 2003,Keane et al., 1996,Le Pera et al., 2005). In addition, DEP-1/PTP $\eta$ participates in the control of cell differentiation, being its expression increased in differentiated breast cancer cells (Keane et al., 1996) and induced by differentiating agents in normal thyroid cells (Keane et al., 1996,Martelli et al., 1998). On the contrary, DEP-1/PTP $\eta$ expression is down-regulated after oncogene-dependent thyroid cell transformation, as well as in malignant human thyroid tumors (Florio et al., 1997,Martelli et al., 1998).

The role of this PTP in SSTR signalling was recognized studying the effects of SST in the rat thyroid cell line $\mathrm{PC} \mathrm{Cl} 3$. In this cell line, a cell cycle arrest in G1, via the PTP-dependent overexpression of the CDKI p27 $7^{\mathrm{kip} 1}$, was observed in response to SST (Florio et al., 1996,Florio et al., 2001). However, when these cells were transformed by the overexpression of different oncogenes (E1A, middle T, mos) SST was ineffective as an antiproliferative agent (Florio et al., 1996,Florio et al., 1997,Florio et al., 2001). Interestingly, in mos-transfected cells, the loss of the SST effects on cell proliferation occurred in the presence of activated SHP-2 that caused the dephosphorylation and inactivation of the insulin receptor (Florio et al., 2001). It was observed that, 
in $\mathrm{PC} \mathrm{Cl3} \mathrm{cells,} \mathrm{the} \mathrm{oncogene-induced} \mathrm{cell} \mathrm{transformation} \mathrm{caused} \mathrm{the} \mathrm{selective} \mathrm{loss} \mathrm{of} \mathrm{the}$ expression of DEP-1/PTP $\eta$ as potential mechanism of resistance to the antiproliferative effects of SST (Florio et al., 1997,Florio et al., 2001). Indeed, the expression level of other PTPs (SHP-2, РТР $\mu$ ) was not affected in the oncogene transformed cells (Florio et al., 1997,Florio et al., 2001). On the other hand, the re-expression of DEP-1/PTP $\eta$ in these cells completely restored the SST dependent up-regulation of $\mathrm{p} 27^{\mathrm{kip} 1}$ and cell growth arrest (Florio et al., 2001).

The discrepancy in the effects of SHP-2 and DEP-1/PTP $\eta$ in the regulation of cell proliferation was explained according the experimental model used. Indeed, the oncogene mos, used to induce the transformation of $\mathrm{PC} \mathrm{Cl3}$ cells, is a direct MEK activator, thus causing the activation of ERK1/2 MAP kinase, and thus of cell proliferation, also in the presence of SHP-2-induced inhibition of the tyrosine phosphorylation of growth factor receptors. More importantly, these experiments suggested that DEP-1/PTP $\eta$ may act down-stream of MEK, and thus, directly on ERK1/2 (Florio et al., 2001). These results were confirmed studying glioma cell lines in which co-immunoprecipitation experiments showed that SST-activated DEP-1/PTP $\eta$ was directly associated to ERK1/2, causing the dephosphorylation/inactivation of the MAP kinase (Massa et al., 2004a) and the up-regulation of $\mathrm{p}^{\mathrm{kip} 1}$ (Massa et al., 2004b). In PC Cl3 cells the up-regulation of this CDKI was induced through the inhibition of its phosphorylation by ERK1/2, thus preventing its ubiquitination and degradation by the proteasome (Florio et al., 2001). Importantly, in glioma cell lines and primary cultures from human glioblastomas, the responsivity to the cytostatic activity of SST was strictly related to the expression and activation of DEP-1/PTP $\eta$ : in cell lines natively devoid of this PTP, SST can induce cell growth arrest only after the transfection of DEP-1/PTP $\eta$ (but not of other PTPs such as PTP $\alpha$ ), while the overexpression of a dominant negative mutant of DEP-1/PTP $\eta$ revert the antiproliferative activity of SST in the responsive cell lines (Massa et al., 2004a). Since DEP1/PTP $\eta$ expression was observed only in about $1 / 3$ of the 22 human glioblastoma specimens analyzed (Massa et al., 2004a), it was proposed that the frequently contradictory results obtained in vivo, using SST analogs as antitumoral agents, may be related to the heterogeneous expression of down-stream effectors (for example DEP-1/PTP $\eta$ ) rather than SSTR levels, that, on the contrary, are almost constantly detected. However, further studies will be necessary to confirm this hypothesis.

Importantly, DEP-1/PTP $\eta$ may also represent a possible target of SSTR in endothelial cells to inhibit tumoral angiogenesis. Indeed, although a direct proof has not been provided yet, the activity of DEP-1 was recognized fundamental to block endothelial cell migration and proliferation 
(Lampugnani et al., 2003) and the in vivo and in vitro antiangiogenic activity of SST was dependent on the activation of PTPs (Albini et al., 1999,Badway et al., 2004).

\section{IDENTIFICATION OF MULTIEFFECTOR COMPLEXES}

The activation of SHP-1 by SST analogues was reported to be dependent on the increase in the phosphorylation state of this PTP (Lopez et al., 1997). Thus, it was proposed that this effect may involve the activation of tyrosine kinases. Indeed, the activity of the cytosolic tyrosine kinase Jak2 was proved to be necessary for both the activation of SHP-1 and the inhibition of proliferation induced by SSTR2, in AR4-2J pancreatic cancer cells (Hortala et al., 2003). In this model, in resting conditions SSTR2, Jak2 and SHP-1 are associated in a common signalling complex: upon SST analogue treatment, JAK2 is activated and its responsible of SHP-1 phosphorylation and activation. In their active form both Jak2 and SHP-1 rapidly dissociate from the receptor with active SHP-1 able to revert HMW FGF-2 dependent cell proliferation (Hortala et al., 2003). Moreover, other PTPs (SHP-2) and cytosolic tyrosine kinases (Src) were subsequently detected in a multi-effector complex associated to SSTR2 in AR4-2J (Ferjoux et al., 2003). It was proposed that the cytostatic effects of SST analogues, via SSTR2 activation, were the results of the sequential activation of kinases and phosphatases, with the SHP-2 activation by Src representing an absolute requirement for the SHP-1 receptor association and its subsequent activation (Ferjoux et al., 2003).

In both glioma and thyroid cells, SST caused the activation of two PTPs: SHP-2 that is active on tyrosine kinase receptors and DEP-1/PTP $\eta$ that directly dephosphorylate ERK1/2. However, in the same way described for SSTR2 and SHP-1, the activation of DEP-1/PTP $\eta$ by SSTR1 involved a multi-effector complex, comprising both kinases and PTPs. In CHO-K1 cells expressing SSTR1 (or in C6 glioma cells treated with a SSTR1 selective agonists, BIM23926) it was shown that, in resting conditions, a large multimeric protein aggregation occurred in proximity of SSTR1 including, in addition to the receptor, the G protein, Jak2, SHP-2, Src and DEP-1/PTP $\eta$ (Arena et al., 2007). To be activated DEP-1/PTP $\eta$ required the sequential activation of Jak2 (G protein-mediated), that phosphorylated SHP-2. Upon phosphorylation, SHP-2 increases its activity (likely via the removal of the SH2 domain from the catalytic site), dissociates from the receptor and dephosphorylates the inhibitory tyrosine on Src C-terminus. Active Src, in turn, tyrosine phosphorylates DEP-1/PTP $\eta$ causing the sustained activity of this PTP that dephosphorylates and inactivates ERK1/2 (Arena et al., 2007).

Thus, the identification in different cell models that similar effector cascades, activated by diverse SSTRs (SSTR1 and SSTR2) and involving a similar interplay of tyrosine kinases and PTPs (Jak2, SHP-2, Src), lead to the activation of a final effector PTP (SHP-1 or DEP-1/PTP $)$ (Arena et al., 
2007,Ferjoux et al., 2003), suggests that this multieffector pathway may represent a common modular mechanism by which cytostatic effects are induced by SST (Figure 2).

\section{CONCLUSIONS}

In the last years the possible modulation of PTP activity in the control of cell proliferation acquired the same relevance as the inhibition of tyrosine kinases and, although the understanding of the molecular mechanisms involved is still at the beginning, certainly it will represent an important goal in the next future. In particular, the recently discovered multieffector complexes regulating the concerted activities of tyrosine kinases and PTPs to modulate cell proliferation represent a significant progression in the comprehension of the biology of SSTRs. In this respect the studies that analyzed the regulation of the activity of specific PTPs by SSTRs opened a completely novel perspective that may allow the reconsideration of the antiproliferative potential of SST analogues.

\section{ACKNOWLEDGMENTS}

This work was supported by a grant from the Italian Association for Cancer Research (AIRC)

\section{REFERENCES}

Albini, A., Florio, T., Giunciuglio, D., Masiello, L., Carlone, S., Corsaro, A., Thellung, S., Cai, T., Noonan, D.M. and Schettini, G. 1999. Somatostatin controls Kaposi's sarcoma tumor growth through inhibition of angiogenesis. Faseb J 13, 647-655.

Alonso, A., Sasin, J., Bottini, N., Friedberg, I., Friedberg, I., Osterman, A., Godzik, A., Hunter, T., Dixon, J. and Mustelin, T. 2004. Protein tyrosine phosphatases in the human genome. Cell 117, 699-711.

Andersen, J.N., Jansen, P.G., Echwald, S.M., Mortensen, O.H., Fukada, T., Del Vecchio, R., Tonks, N.K. and Moller, N.P. 2004. A genomic perspective on protein tyrosine phosphatases: gene structure, pseudogenes, and genetic disease linkage. Faseb J 18, 8-30.

Arena, S., Pattarozzi, A., Massa, A., Esteve, J.P., Iuliano, R., Fusco, A., Susini, C. and Florio, T. 2007. An intracellular multi-effector complex mediates somatostatin receptor 1 activation of phospho-tyrosine phosphatase eta. Mol Endocrinol 21, 229-246.

Aricescu, A.R., McKinnell, I.W., Halfter, W. and Stoker, A.W. 2002. Heparan sulfate proteoglycans are ligands for receptor protein tyrosine phosphatase sigma. Mol Cell Biol 22, 1881-1892.

Badway, A.C., West, F.M., Tente, S.M. and Blake, A.D. 2004. Somatostatin regulates intracellular signaling in human carotid endothelial cells. Biochem Biophys Res Commun 319, 1222 1227.

Bedecs, K., Elbaz, N., Sutren, M., Masson, M., Susini, C., Strosberg, A.D. and Nahmias, C. 1997. Angiotensin II type 2 receptors mediate inhibition of mitogen-activated protein kinase cascade and functional activation of SHP-1 tyrosine phosphatase. Biochem J 325 ( Pt 2), 449-454.

Bensaid, M., Tahiri-Jouti, N., Cambillau, C., Viguerie, N., Colas, B., Vidal, C., Tauber, J.P., Esteve, J.P., Susini, C. and Vaysse, N. 1992. Basic fibroblast growth factor induces proliferation of a rat pancreatic cancer cell line. Inhibition by somatostatin. Int J Cancer 50, 796-799.

Bilwes, A.M., den Hertog, J., Hunter, T. and Noel, J.P. 1996. Structural basis for inhibition of receptor protein-tyrosine phosphatase-alpha by dimerization. Nature 382, 555-559. 
Bousquet, C., Delesque, N., Lopez, F., Saint-Laurent, N., Esteve, J.P., Bedecs, K., Buscail, L., Vaysse, N. and Susini, C. 1998. sst2 somatostatin receptor mediates negative regulation of insulin receptor signaling through the tyrosine phosphatase SHP-1. J Biol Chem 273, 70997106.

Bousquet, C., Guillermet-Guibert, J., Saint-Laurent, N., Archer-Lahlou, E., Lopez, F., Fanjul, M., Ferrand, A., Fourmy, D., Pichereaux, C., Monsarrat, B., Pradayrol, L., Esteve, J.P. and Susini, C. 2006. Direct binding of p85 to sst2 somatostatin receptor reveals a novel mechanism for inhibiting PI3K pathway. Embo J 25, 3943-3954.

Brady-Kalnay, S.M., Flint, A.J. and Tonks, N.K. 1993. Homophilic binding of PTP mu, a receptortype protein tyrosine phosphatase, can mediate cell-cell aggregation. J Cell Biol 122, 961 972.

Brevini, T.A., Bianchi, R. and Motta, M. 1993. Direct inhibitory effect of somatostatin on the growth of the human prostatic cancer cell line LNCaP: possible mechanism of action. J Clin Endocrinol Metab 77, 626-631.

Buscail, L., Delesque, N., Esteve, J.P., Saint-Laurent, N., Prats, H., Clerc, P., Robberecht, P., Bell, G.I., Liebow, C., Schally, A.V. and et al. 1994. Stimulation of tyrosine phosphatase and inhibition of cell proliferation by somatostatin analogues: mediation by human somatostatin receptor subtypes SSTR1 and SSTR2. Proc Natl Acad Sci U S A 91, 2315-2319.

Cattaneo, M.G., Amoroso, D., Gussoni, G., Sanguini, A.M. and Vicentini, L.M. 1996. A somatostatin analogue inhibits MAP kinase activation and cell proliferation in human neuroblastoma and in human small cell lung carcinoma cell lines. FEBS Lett 397, 164-168.

Chagnon, M.J., Uetani, N. and Tremblay, M.L. 2004. Functional significance of the LAR receptor protein tyrosine phosphatase family in development and diseases. Biochem Cell Biol 82, 664-675.

Colas, B., Cambillau, C., Buscail, L., Zeggari, M., Esteve, J.P., Lautre, V., Thomas, F., Vaysse, N. and Susini, C. 1992. Stimulation of a membrane tyrosine phosphatase activity by somatostatin analogues in rat pancreatic acinar cells. Eur J Biochem 207, 1017-1024.

Dent, P., Wang, Y., Gu, Y.Z., Wood, S.L., Reardon, D.B., Mangues, R., Pellicer, A., Schonbrunn, A. and Sturgill, T.W. 1997. S49 cells endogenously express subtype 2 somatostatin receptors which couple to increase protein tyrosine phosphatase activity in membranes and down-regulate Raf-1 activity in situ. Cell Signal 9, 539-549.

Ferjoux, G., Lopez, F., Esteve, J.P., Ferrand, A., Vivier, E., Vely, F., Saint-Laurent, N., Pradayrol, L., Buscail, L. and Susini, C. 2003. Critical role of Src and SHP-2 in sst2 somatostatin receptor-mediated activation of SHP-1 and inhibition of cell proliferation. Mol Biol Cell 14, 3911-3928.

Ferone, D., Pivonello, R., Van Hagen, P.M., Dalm, V.A., Lichtenauer-Kaligis, E.G., Waaijers, M., Van Koetsveld, P.M., Mooy, D.M., Colao, A., Minuto, F., Lamberts, S.W. and Hofland, L.J. 2002. Quantitative and functional expression of somatostatin receptor subtypes in human thymocytes. Am J Physiol Endocrinol Metab 283, E1056-1066.

Ferrante, E., Pellegrini, C., Bondioni, S., Peverelli, E., Locatelli, M., Gelmini, P., Luciani, P., Peri, A., Mantovani, G., Bosari, S., Beck-Peccoz, P., Spada, A. and Lania, A. 2006. Octreotide promotes apoptosis in human somatotroph tumor cells by activating somatostatin receptor type 2. Endocr Relat Cancer 13, 955-962.

Florio, T., Pan, M.G., Newman, B., Hershberger, R.E., Civelli, O. and Stork, P.J. 1992. Dopaminergic inhibition of DNA synthesis in pituitary tumor cells is associated with phosphotyrosine phosphatase activity. J Biol Chem 267, 24169-24172.

Florio, T., Rim, C., Hershberger, R.E., Loda, M. and Stork, P.J. 1994. The somatostatin receptor SSTR1 is coupled to phosphotyrosine phosphatase activity in CHO-K1 cells. Mol Endocrinol 8, 1289-1297.

Florio, T., Scorziello, A., Fattore, M., D'Alto, V., Salzano, S., Rossi, G., Berlingieri, M.T., Fusco, A. and Schettini, G. 1996. Somatostatin inhibits PC Cl3 thyroid cell proliferation through the 
modulation of phosphotyrosine activity. Impairment of the somatostatinergic effects by stable expression of E1A viral oncogene. J Biol Chem 271, 6129-6136.

Florio, T., Scorziello, A., Thellung, S., Salzano, S., Berlingieri, M.T., Fusco, A. and Schettini, G. 1997. Oncogene transformation of $\mathrm{PC} \mathrm{Cl3}$ clonal thyroid cell line induces an autonomous pattern of proliferation that correlates with a loss of basal and stimulated phosphotyrosine phosphatase activity. Endocrinology 138, 3756-3763.

Florio, T., Thellung, S., Arena, S., Corsaro, A., Spaziante, R., Gussoni, G., Acuto, G., Giusti, M., Giordano, G. and Schettini, G. 1999a. Somatostatin and its analog lanreotide inhibit the proliferation of dispersed human non-functioning pituitary adenoma cells in vitro. Eur $\mathrm{J}$ Endocrinol 141, 396-408.

Florio, T., Yao, H., Carey, K.D., Dillon, T.J. and Stork, P.J. 1999b. Somatostatin activation of mitogen-activated protein kinase via somatostatin receptor 1 (SSTR1). Mol Endocrinol 13, 24-37.

Florio, T., Thellung, S., Arena, S., Corsaro, A., Bajetto, A., Schettini, G. and Stork, P.J. 2000. Somatostatin receptor 1 (SSTR1)-mediated inhibition of cell proliferation correlates with the activation of the MAP kinase cascade: role of the phosphotyrosine phosphatase SHP-2. J Physiol Paris 94, 239-250.

Florio, T., Arena, S., Thellung, S., Iuliano, R., Corsaro, A., Massa, A., Pattarozzi, A., Bajetto, A., Trapasso, F., Fusco, A. and Schettini, G. 2001. The activation of the phosphotyrosine phosphatase eta (r-PTP eta) is responsible for the somatostatin inhibition of PC Cl3 thyroid cell proliferation. Mol Endocrinol 15, 1838-1852.

Florio, T., Morini, M., Villa, V., Arena, S., Corsaro, A., Thellung, S., Culler, M.D., Pfeffer, U., Noonan, D.M., Schettini, G. and Albini, A. 2003a. Somatostatin inhibits tumor angiogenesis and growth via somatostatin receptor-3-mediated regulation of endothelial nitric oxide synthase and mitogen-activated protein kinase activities. Endocrinology 144, 1574-1584.

Florio, T., Thellung, S., Corsaro, A., Bocca, L., Arena, S., Pattarozzi, A., Villa, V., Massa, A., Diana, F., Schettini, D., Barbieri, F., Ravetti, J.L., Spaziante, R., Giusti, M. and Schettini, G. 2003b. Characterization of the intracellular mechanisms mediating somatostatin and lanreotide inhibition of DNA synthesis and growth hormone release from dispersed human GH-secreting pituitary adenoma cells in vitro. Clin Endocrinol (Oxf) 59, 115-128.

Fox, A.N. and Zinn, K. 2005. The heparan sulfate proteoglycan syndecan is an in vivo ligand for the Drosophila LAR receptor tyrosine phosphatase. Curr Biol 15, 1701-1711.

Garton, A.J., Flint, A.J. and Tonks, N.K. 1996. Identification of p130(cas) as a substrate for the cytosolic protein tyrosine phosphatase PTP-PEST. Mol Cell Biol 16, 6408-6418.

Guillermet-Guibert, J., Saint-Laurent, N., Davenne, L., Rochaix, P., Cuvillier, O., Culler, M.D., Pradayrol, L., Buscail, L., Susini, C. and Bousquet, C. 2007. Novel synergistic mechanism for sst2 somatostatin and TNFalpha receptors to induce apoptosis: crosstalk between NFkappaB and JNK pathways. Cell Death Differ 14, 197-208.

Guillermet, J., Saint-Laurent, N., Rochaix, P., Cuvillier, O., Levade, T., Schally, A.V., Pradayrol, L., Buscail, L., Susini, C. and Bousquet, C. 2003. Somatostatin receptor subtype 2 sensitizes human pancreatic cancer cells to death ligand-induced apoptosis. Proc Natl Acad Sci U S A $100,155-160$.

Held-Feindt, J., Forstreuter, F., Pufe, T. and Mentlein, R. 2001. Influence of the somatostatin receptor sst 2 on growth factor signal cascades in human glioma cells. Brain Res Mol Brain Res 87, 12-21.

Hierowski, M.T., Liebow, C., du Sapin, K. and Schally, A.V. 1985. Stimulation by somatostatin of dephosphorylation of membrane proteins in pancreatic cancer MIA PaCa-2 cell line. FEBS Lett 179, 252-256.

Hortala, M., Ferjoux, G., Estival, A., Bertrand, C., Schulz, S., Pradayrol, L., Susini, C. and Clemente, F. 2003. Inhibitory role of the somatostatin receptor SST2 on the intracrine- 
regulated cell proliferation induced by the 210 -amino acid fibroblast growth factor-2 isoform: implication of JAK2. J Biol Chem 278, 20574-20581.

Imai, A., Takagi, H., Furui, T., Horibe, S., Fuseya, T. and Tamaya, T. 1996. Evidence for coupling of phosphotyrosine phosphatase to gonadotropin-releasing hormone receptor in ovarian carcinoma membrane. Cancer 77, 132-137.

Iuliano, R., Trapasso, F., Le Pera, I., Schepis, F., Sama, I., Clodomiro, A., Dumon, K.R., Santoro, M., Chiariotti, L., Viglietto, G. and Fusco, A. 2003. An adenovirus carrying the rat protein tyrosine phosphatase eta suppresses the growth of human thyroid carcinoma cell lines in vitro and in vivo. Cancer Res 63, 882-886.

Keane, M.M., Lowrey, G.A., Ettenberg, S.A., Dayton, M.A. and Lipkowitz, S. 1996. The protein tyrosine phosphatase DEP-1 is induced during differentiation and inhibits growth of breast cancer cells. Cancer Res 56, 4236-4243.

Kovalenko, M., Denner, K., Sandstrom, J., Persson, C., Gross, S., Jandt, E., Vilella, R., Bohmer, F. and Ostman, A. 2000. Site-selective dephosphorylation of the platelet-derived growth factor beta-receptor by the receptor-like protein-tyrosine phosphatase DEP-1. J Biol Chem 275, 16219-16226.

Lahlou, H., Saint-Laurent, N., Esteve, J.P., Eychene, A., Pradayrol, L., Pyronnet, S. and Susini, C. 2003. sst2 Somatostatin receptor inhibits cell proliferation through Ras-, Rap1-, and B-Rafdependent ERK2 activation. J Biol Chem 278, 39356-39371.

Lampugnani, M.G., Zanetti, A., Corada, M., Takahashi, T., Balconi, G., Breviario, F., Orsenigo, F., Cattelino, A., Kemler, R., Daniel, T.O. and Dejana, E. 2003. Contact inhibition of VEGFinduced proliferation requires vascular endothelial cadherin, beta-catenin, and the phosphatase DEP-1/CD148. J Cell Biol 161, 793-804.

Le Pera, I., Iuliano, R., Florio, T., Susini, C., Trapasso, F., Santoro, M., Chiariotti, L., Schettini, G., Viglietto, G. and Fusco, A. 2005. The rat tyrosine phosphatase eta increases cell adhesion by activating c-Src through dephosphorylation of its inhibitory phosphotyrosine residue. Oncogene 24, 3187-3195.

Liu, D., Martino, G., Thangaraju, M., Sharma, M., Halwani, F., Shen, S.H., Patel, Y.C. and Srikant, C.B. 2000. Caspase-8-mediated intracellular acidification precedes mitochondrial dysfunction in somatostatin-induced apoptosis. J Biol Chem 275, 9244-9250.

Lopez, F., Esteve, J.P., Buscail, L., Delesque, N., Saint-Laurent, N., Theveniau, M., Nahmias, C., Vaysse, N. and Susini, C. 1997. The tyrosine phosphatase SHP-1 associates with the sst2 somatostatin receptor and is an essential component of sst2-mediated inhibitory growth signaling. J Biol Chem 272, 24448-24454.

Martelli, M.L., Trapasso, F., Bruni, P., Berlingieri, M.T., Battaglia, C., Vento, M.T., Belletti, B., Iuliano, R., Santoro, M., Viglietto, G. and Fusco, A. 1998. Protein tyrosine phosphatase-eta expression is upregulated by the PKA-dependent and is downregulated by the PKCdependent pathways in thyroid cells. Exp Cell Res 245, 195-202.

Massa, A., Barbieri, F., Aiello, C., Arena, S., Pattarozzi, A., Pirani, P., Corsaro, A., Iuliano, R., Fusco, A., Zona, G., Spaziante, R., Florio, T. and Schettini, G. 2004a. The expression of the phosphotyrosine phosphatase DEP-1/PTPeta dictates the responsivity of glioma cells to somatostatin inhibition of cell proliferation. J Biol Chem 279, 29004-29012.

Massa, A., Barbieri, F., Aiello, C., Iuliano, R., Arena, S., Pattarozzi, A., Corsaro, A., Villa, V., Fusco, A., Zona, G., Spaziante, R., Schettini, G. and Florio, T. 2004b. The phosphotyrosine phosphatase eta mediates somatostatin inhibition of glioma proliferation via the dephosphorylation of ERK1/2. Ann N Y Acad Sci 1030, 264-274.

Meng, K., Rodriguez-Pena, A., Dimitrov, T., Chen, W., Yamin, M., Noda, M. and Deuel, T.F. 2000. Pleiotrophin signals increased tyrosine phosphorylation of beta beta-catenin through inactivation of the intrinsic catalytic activity of the receptor-type protein tyrosine phosphatase beta/zeta. Proc Natl Acad Sci U S A 97, 2603-2608. 
Milarski, K.L., Zhu, G., Pearl, C.G., McNamara, D.J., Dobrusin, E.M., MacLean, D., Thieme-Sefler, A., Zhang, Z.Y., Sawyer, T., Decker, S.J. and et al. 1993. Sequence specificity in recognition of the epidermal growth factor receptor by protein tyrosine phosphatase $1 \mathrm{~B}$. J Biol Chem 268, 23634-23639.

Murphy, K., Gerzanich, V., Zhou, H., Ivanova, S., Dong, Y., Hoffman, G., West, G.A., Winn, H.R. and Simard, J.M. 2003. Adenosine-A2a receptor down-regulates cerebral smooth muscle Ltype $\mathrm{Ca} 2+$ channel activity via protein tyrosine phosphatase, not cAMP-dependent protein kinase. Mol Pharmacol 64, 640-649.

Murphy, L.O., Smith, S., Chen, R.H., Fingar, D.C. and Blenis, J. 2002. Molecular interpretation of ERK signal duration by immediate early gene products. Nat Cell Biol 4, 556-564.

Nam, H.J., Poy, F., Saito, H. and Frederick, C.A. 2005. Structural basis for the function and regulation of the receptor protein tyrosine phosphatase CD45. J Exp Med 201, 441-452.

Neel, B.G. and Tonks, N.K. 1997. Protein tyrosine phosphatases in signal transduction. Curr Opin Cell Biol 9, 193-204.

Ostman, A., Hellberg, C. and Bohmer, F.D. 2006. Protein-tyrosine phosphatases and cancer. Nat Rev Cancer 6, 307-320.

Pages, P., Benali, N., Saint-Laurent, N., Esteve, J.P., Schally, A.V., Tkaczuk, J., Vaysse, N., Susini, C. and Buscail, L. 1999. sst2 somatostatin receptor mediates cell cycle arrest and induction of p27(Kip1). Evidence for the role of SHP-1. J Biol Chem 274, 15186-15193.

Pan, M.G., Florio, T. and Stork, P.J. 1992. G protein activation of a hormone-stimulated phosphatase in human tumor cells. Science 256, 1215-1217.

Pan, M.G., Rim, C., Lu, K.P., Florio, T. and Stork, P.J. 1993. Cloning and expression of two structurally distinct receptor-linked protein-tyrosine phosphatases generated by RNA processing from a single gene. J Biol Chem 268, 19284-19291.

Pulido, R., Zuniga, A. and Ullrich, A. 1998. PTP-SL and STEP protein tyrosine phosphatases regulate the activation of the extracellular signal-regulated kinases ERK1 and ERK2 by association through a kinase interaction motif. Embo J 17, 7337-7350.

Reardon, D.B., Wood, S.L., Brautigan, D.L., Bell, G.I., Dent, P. and Sturgill, T.W. 1996. Activation of a protein tyrosine phosphatase and inactivation of Raf-1 by somatostatin. Biochem J 314 ( Pt 2), 401-404.

Reardon, D.B., Dent, P., Wood, S.L., Kong, T. and Sturgill, T.W. 1997. Activation in vitro of somatostatin receptor subtypes 2,3 , or 4 stimulates protein tyrosine phosphatase activity in membranes from transfected Ras-transformed NIH 3T3 cells: coexpression with catalytically inactive SHP-2 blocks responsiveness. Mol Endocrinol 11, 1062-1069.

Reyl, F.J. and Lewin, M.J. 1982. Intracellular receptor for somatostatin in gastric mucosal cells: decomposition and reconstitution of somatostatin-stimulated phosphoprotein phosphatases. Proc Natl Acad Sci U S A 79, 978-982.

Ruivenkamp, C.A., van Wezel, T., Zanon, C., Stassen, A.P., Vlcek, C., Csikos, T., Klous, A.M., Tripodis, N., Perrakis, A., Boerrigter, L., Groot, P.C., Lindeman, J., Mooi, W.J., Meijjer, G.A., Scholten, G., Dauwerse, H., Paces, V., van Zandwijk, N., van Ommen, G.J. and Demant, P. 2002. Ptprj is a candidate for the mouse colon-cancer susceptibility locus Scc1 and is frequently deleted in human cancers. Nat Genet 31, 295-300.

Sharma, K., Patel, Y.C. and Srikant, C.B. 1996. Subtype-selective induction of wild-type p53 and apoptosis, but not cell cycle arrest, by human somatostatin receptor 3. Mol Endocrinol 10, 1688-1696.

Sharma, K. and Srikant, C.B. 1998. G protein coupled receptor signaled apoptosis is associated with activation of a cation insensitive acidic endonuclease and intracellular acidification. Biochem Biophys Res Commun 242, 134-140.

Sorby, M., Sandstrom, J. and Ostman, A. 2001. An extracellular ligand increases the specific activity of the receptor-like protein tyrosine phosphatase DEP-1. Oncogene 20, 5219-5224. 
Srikant, C.B. and Shen, S.H. 1996. Octapeptide somatostatin analog SMS 201-995 induces translocation of intracellular PTP1C to membranes in MCF-7 human breast adenocarcinoma cells. Endocrinology 137, 3461-3468.

Thangaraju, M., Sharma, K., Leber, B., Andrews, D.W., Shen, S.H. and Srikant, C.B. 1999a. Regulation of acidification and apoptosis by SHP-1 and Bcl-2. J Biol Chem 274, 2954929557.

Thangaraju, M., Sharma, K., Liu, D., Shen, S.H. and Srikant, C.B. 1999b. Interdependent regulation of intracellular acidification and SHP-1 in apoptosis. Cancer Res 59, 1649-1654.

Theodoropoulou, M., Zhang, J., Laupheimer, S., Paez-Pereda, M., Erneux, C., Florio, T., Pagotto, U. and Stalla, G.K. 2006. Octreotide, a somatostatin analogue, mediates its antiproliferative action in pituitary tumor cells by altering phosphatidylinositol 3-kinase signaling and inducing Zac1 expression. Cancer Res 66, 1576-1582.

Tonks, N.K., Diltz, C.D. and Fischer, E.H. 1988. Purification of the major protein-tyrosinephosphatases of human placenta. J Biol Chem 263, 6722-6730.

Tonks, N.K. and Neel, B.G. 2001. Combinatorial control of the specificity of protein tyrosine phosphatases. Curr Opin Cell Biol 13, 182-195.

Tonks, N.K. 2005. Redox redux: revisiting PTPs and the control of cell signaling. Cell 121, 667670.

Tonks, N.K. 2006. Protein tyrosine phosphatases: from genes, to function, to disease. Nat Rev Mol Cell Biol 7, 833-846.

Tsuzaki, S. and Moses, A.C. 1990. Somatostatin inhibits deoxyribonucleic acid synthesis induced by both thyrotropin and insulin-like growth factor-I in FRTL5 cells. Endocrinology 126, 3131-3138.

Viguerie, N., Tahiri-Jouti, N., Ayral, A.M., Cambillau, C., Scemama, J.L., Bastie, M.J., Knuhtsen, S., Esteve, J.P., Pradayrol, L., Susini, C. and et al. 1989. Direct inhibitory effects of a somatostatin analog, SMS 201-995, on AR4-2J cell proliferation via pertussis toxinsensitive guanosine triphosphate-binding protein-independent mechanism. Endocrinology $124,1017-1025$.

Weckbecker, G., Lewis, I., Albert, R., Schmid, H.A., Hoyer, D. and Bruns, C. 2003. Opportunities in somatostatin research: biological, chemical and therapeutic aspects. Nat Rev Drug Discov 2, 999-1017.

Yu, Z., Su, L., Hoglinger, O., Jaramillo, M.L., Banville, D. and Shen, S.H. 1998. SHP-1 associates with both platelet-derived growth factor receptor and the p85 subunit of phosphatidylinositol 3-kinase. J Biol Chem 273, 3687-3694.

Zapata, P.D., Ropero, R.M., Valencia, A.M., Buscail, L., Lopez, J.I., Martin-Orozco, R.M., Prieto, J.C., Angulo, J., Susini, C., Lopez-Ruiz, P. and Colas, B. 2002. Autocrine regulation of human prostate carcinoma cell proliferation by somatostatin through the modulation of the SH2 domain containing protein tyrosine phosphatase (SHP)-1. J Clin Endocrinol Metab 87, 915-926.

Zatelli, M.C., Piccin, D., Tagliati, F., Bottoni, A., Luchin, A. and degli Uberti, E.C. 2005. SRC homology-2-containing protein tyrosine phosphatase-1 restrains cell proliferation in human medullary thyroid carcinoma. Endocrinology 146, 2692-2698.

Zeggari, M., Esteve, J.P., Rauly, I., Cambillau, C., Mazarguil, H., Dufresne, M., Pradayrol, L., Chayvialle, J.A., Vaysse, N. and Susini, C. 1994. Co-purification of a protein tyrosine phosphatase with activated somatostatin receptors from rat pancreatic acinar membranes. Biochem J 303 ( Pt 2), 441-448.

Zheng, X.M., Wang, Y. and Pallen, C.J. 1992. Cell transformation and activation of pp60c-src by overexpression of a protein tyrosine phosphatase. Nature 359, 336-339. 


\section{LEGENDS TO FIGURES}

\section{FIGURE 1}

Schematic representation of the classical PTPs.

The structure of the principal components of the receptor-like and non-transmembrane PTP subfamilies is detailed. It is important to note that the this subdivision is not absolute since the use of alternative promoters or alternative splicing can originate either receptor-like or nontransmembrane enzymes (for example in the case of PTPE or GLEPP1)(Tonks, 2006).

In the box, the legend for the symbols depicting the various regulatory domains is reported.

\section{FIGURE 2}

Schematic representation of the intracellular cascades leading to the activation of the final effector PTPs (DEP-1/PTP $\eta$ and SHP-1).

The activation of SSTR1 and SSTR2 via a pertussis toxin sensitive G protein leads to the sequential activation of tyrosine kinases and PTPs that ultimately induce cell groth arrest (for a detailed description, see the text).

In the top of the figure is reported the cell types in which the individual pathways were described. 

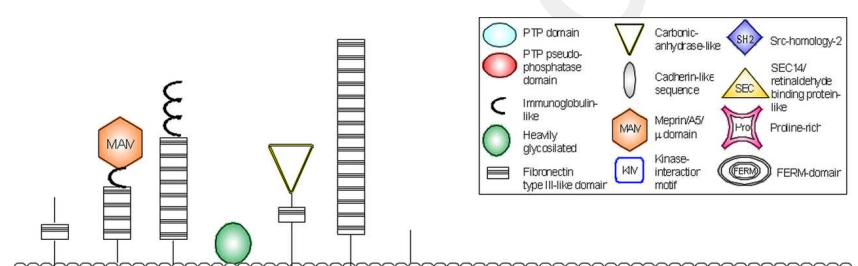

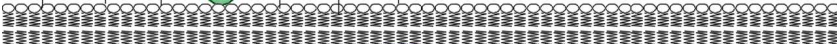

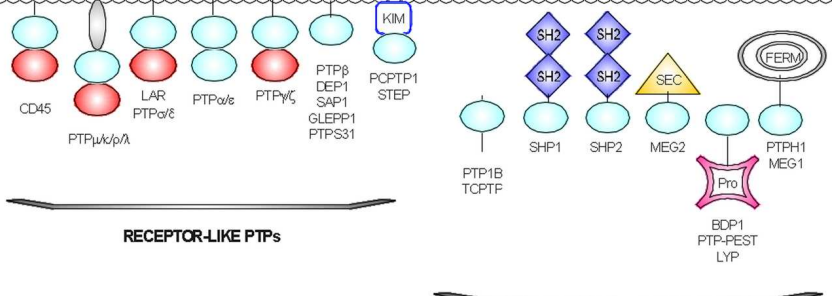

NON-TRANSMEMBRANE PTPS

Page 19 of 20 


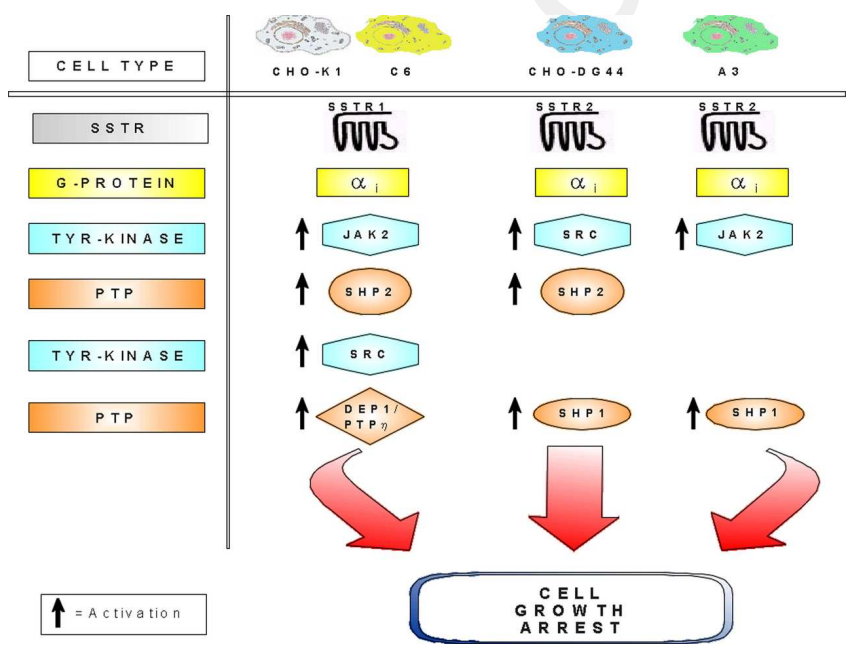

